\title{
CONGRESO CONSTITUYENTE DEL CENTRO DEMOCRATICO Y SOCIAL
}

El Palacio de Exposiciones y Congresos de Madrid fue escenario, durante los días 2 y 3 de octubre, de la celebración del Congreso constituyente del Centro Democrático y Social, que debe su fundación al ex presidente del Gabierno don Adolfo Suárez.

Entre otras, de las ponencias que fueron discutidas y aprobadas en su Congreso constituyente destacan las siguientes:

\section{IDEOLOGIA}

E1 CDS nace con el objetivo fundamental de satisfacer una necesidad histórica y una demanda política: la creación de un partido de centro progresista, capaz de renovar la ilusión del pueblo español ante su futuro y de evitar en la vida política la tensión entre dos tendencias opuestas y radicalizadas.

$\mathrm{El}$ sistema de valores que inspira al CDS se fundamenta en el personalismo comunitario, lo que significa la asunción del valor supremo de la persona, entendiendo a ésta no sólo como individuo, sino como sujeto que en la vida histórica y social se realiza mediante la cooperación solidaria en las comunidades en que está inserto. El eje central de la ideología del CDS está constituido por la persona, su libertad y dignidad. Pero el hombre es un ser social e histórico por naturaleza; de ahí que frente a la ética individualista de los hombres y de los pueblos, el CDS afirme el prevalecimiento de la ética universalista y solidaria de la humanidad.

Una concepción del mundo de esta naturaleza entraña un proyecto político de transformación permanente de los hombres y de las instituciones. Para el CDS, el Estado moderno no puede ser visto como la cristalización definitiva e inamovible de organización política de los pueblos. La idea de que el Estado se ha hecho por el hombre y para el hombre, y no el hombre para el Estado, constituye un postulado básico dentro de los principios ideológicos del CDS.

Parte el CDS de la idea de que persona y sociedad se condicionan mutuamente en su desarrollo. De esta forma, la función primordial de las instituciones sociales consiste en la creación de las condiciones que posibiliten el desarrollo libre, responsable, digno y solidario de las personas a las que sirven.

Por otra parte, considerando que la libertad real de la persona constituye una difícil conquista que es preciso realizar cada día, el CDS afirma que en una socie- 
dad comunitaria se han de reconocer y garantizar necesariamente todos los derechos y libertades definidos en la Declaración Universal de Derechos del Hombre.

Así pues, el CDS fundamenta su ideología en la dignidad y libertad de la persona humana y en los principios de justicia y solidaridad, que son precisamente quienes garantizan aquéllas.

\section{POLITICA EXTERIOR}

El CDS estima esencial la presencia de España en el concierto de las naciones $\mathrm{y}$ en los organismos internacionales $\mathrm{y}$, muy especialmente, en todos aquellos que tengan como objetivos la defensa de los derechos humanos y la solidaridad internacional.

La línea a seguir por el CDS en política exterior puede sintetizarse en los siguientes puntos:

- Defensa de la total integridad del territorio nacional en los términos previstos en la Constitución.

- Negociación de las condiciones de integración en la OTAN, tras un amplio debate parlamentario en el que tengan ocasión de pronunciarse las fuerzas políticas del país respecto a las mínimas condiciones y contrapartidas exigibles por nuestra parte.

- Incorporación en la Comunidad Económica Europea desde posiciones de firmeza, exigiendo de la CEE, y de sus componentes por separado, compromisos firmes y claros.

- Recuperación de Gibraltar, sin perjuicio de los derechos de los actuales habitantes del Peñón.

- Intensificación de la cooperación española en los procesos económicos y sociales de los países hispanoamericanos y en sus proyectos de integración multinacional. Potenciación del intercambio cultural con tales países.

- Fomento de las relaciones con el mundo árabe, tanto en el terreno cultural y educativo como en el económico y tecnológico.

- Tener presente a la hora de instrumentalizar la política exterior la realidad y posibilidades de la emigración española, considerando la defensa de los derechos de los emigrantes como objetivo urgente e irrenunciable.

\section{DEFENSA}

La defensa nacional es considerada por el CDS como un asunto de máxima prioridad. España participa en la defensa del mundo libre al que pertenece. Por ello, el CDS estima que debe estar integrada en los organismos de la Europa Occidental, ejercer una influencia real en el Mediterráneo y especialmente en el mundo árabe, y establecer acuerdos con Iberoamérica. Nuestra política de Defensa, a juicio del CDS, tiene como principales misiones:

- Garantizar la seguridad e independencia del territorio español.

- Integridad de todos nuestros territorios.

- Soberanía de nuestros espacios marítimos y aéreos.

- Garantizar nuestros intereses internacionales.

- Defender la Constitución.

Asimismo, el CDS estima que los Ejércitos españoles deben mejorar su profesionalidad y disminuir sus volúmenes en beneficio de una mejor preparación y calidad. 
Otros objetivos en política de Defensa serían:

- Reducción del servicio militar a un año de prestación, procurando causar las menores incidencias posibles en la población que lo cumple.

- Regulación, a través de ley, de la enseñanza militar, con el fin de conformarla a los principios constitucionales y a los tiempos actuales, tanto en lo técnico como en lo humano, para evitar cualquier aislamiento entre civiles y militares.

- Elaboración de un nuevo Código de Justicia Militar adecuado a un país democrático.

\section{LIBERTADES PUBLICAS Y SEGURIDAD CIUDADANA}

El reconocimiento y protección de las libertades individuales constituye un aspecto básico del programa del CDS. La imparcialidad y la eficacia son, a juicio de este partido, las únicas reglas que pueden garantizar una auténtica tutela por parte de los poderes públicos; imparcialidad en el reconocimiento y desarrollo de aquellas libertades que implican una opción, y eficacia en la protección de aquellas que generan auténticos derechos individuales y de aquellos derechos que de no protegerse colocarían al ciudadano en una auténtica situación de indefensión. Así pues, la protección eficaz que propugna el CDS requiere, para ser tal, dos requisitos: primero, que esté encomendada a los jueces; y segundo, que sea rápida y tenga la misma publicidad que tuvo, en su momento, la lesión del derecho de que se trate.

Respecto a la seguridad ciudadana, el CDS la entiende como la posibilidad del libre ejercicio de los derechos y libertades en la seguridad de que el Estado dispone de los medios y de la voluntad necesarios para defender ese ejercicio y reponer los derechos y libertades que hayan sido transgredidos.

El afianzamiento de la seguridad ciudadana constituye un objetivo prioritario del CDS, que propugna para ello:

- Armonización del ejercicio de las libertades públicas con el respeto a los derechos individuales.

- Potenciación de los medios personales y materiales de los Cuerpos y Fuerzas de Seguridad del Estado y defensa de un respaldo popular siempre necesario para la prestación de un servicio difícil como es el de la seguridad ciudadana.

- Regulación de la colaboración entre los distintos Cuerpos y Fuerzas de Seguridad del Estado y de éstos con las policías autónomas y municipales, bajo principios de eficacia.

- Regulación de la función policial, bajo principios de legalidad, apoliticidad, jerarquía y autoridad.

- Regulación del status jurídico de los Cuerpos y Fuerzas de Seguridad del Estado.

- Potenciación de los medios de lucha antiterrorista y denuncia constante de la absoluta falta de justificación de las acciones terroristas.

\section{EDUCACION}

En política educativa, el CDS propone las siguientes medidas:

- Escolarización obligatoria y gratuita hasta los dieciséis años y elevación de esta edad a los dieciocho años, considerando esta segunda edad como objetivo preferente. 
- La creación de centros docentes privados en un marco legal, que establezca las condiciones conforme a las que se otorgarán subvenciones públicas por puesto escolar a estas iniciativas.

- Adecuar los estudios de E. G. B. a la capacidad de los alumnos, hasta lograr una significativa disminución del número de casos de fracaso escolar.

- Potenciación de la formación profesional, como tipo educativo altamente positivo en sí mismo y adecuado a las cambiantes necesidades de la sociedad industrial y a la promoción de empleo.

- Garantizar la autonomía de las Universidades como requisito para la mejora de la enseñanza universitaria. Fomentar la investigación, desburocratizar la enseñanza, selección del profesorado basada en criterios de imparcialidad, méritos y capacidad.

- Creación de un plan de enseñanza permanente de adultos que contribuya a facilitar el acceso a niveles superiores educativos y culturales a todos los españoles.

\section{POLITICA TERRITORIAL}

El CDS tiene como uno de sus principales objetivos la reforma de las Administraciones públicas para que, efectivamente, estas Administraciones estén al servicio de los ciudadanos y cumplan sus funciones asistenciales, culturales y en general de creación de las condiciones de igualdad y progreso que son demandadas en los Estados modernos por los administrados.

La coordinación y colaboración entre las distintas Administraciones territoriales es fundamental para el mejor servicio que se propugna.

La política del CDS en este sentido se asienta en la convicción de que el proceso autonómico y la vida local no son antagónicos, por lo que su política territorial se basa en los siguientes objetivos:

- Finalización del proceso autonómico mediante la pronta aprobación de los Estatutos de Autonomía pendientes aún.

- Reforma del ordenamiento administrativo con el fin de garantizar a los ciudadanos un tratamiento común ante las Administraciones públicas.

- Aplicación y desarrollo de la Ley Orgánica de Financiación de las Comunidades Autónomas con criterios de efectiva solidaridad y con mayor potenciación del criterio de emigración.

- Garantizar los derechos de los funcionarios que hayan de prestar sus servicios en las Comunidades Autónomas.

- Igualación de la función pública local al régimen de la Administración central, respetando en todo caso los principios constitucionales de capacidad y mérito.

\section{CULTURA}

EI CDS considera que la cultura comprende todas las formas peculiares de pensamiento, expresión y acción de cada comunidad concreta, así como las creencias e instituciones que proporcionan el perfil propio de cada sociedad en el proceso de su identificación y transformación a lo largo de la historia.

La política cultural debe permitir al ciudadano estar en condiciones de enjuiciar la información que recibe, participar en el proceso creador de la historia con sus propias y específicas capacidades... 
El CDS propugna una política cultural basada esencialmente en poder satisfacer el derecho a la cultura de todos los ciudadanos, paliando así la desigualdad existente en la comunidad española.

\section{POLITICA FAMILIAR}

El CDS propugna en lo que respecta a la política familiar:

- Reducir la sobrecarga fiscal que soporta el matrimonio en que ambos cónyuges trabajan y eliminarla por debajo de un volumen de ingresos.

- Revisar las actuales prestaciones asistenciales aumentando sustancialmente las destinadas a las familias con menos recursos económicos y mayor número de hijos.

- Extensión de los centros preescolares y guarderías, estableciendo las ayudas oportunas para que la mujer trabajadora pueda confiar sus hijos a centros bien dotados pedagógicamente.

- Adecuar el tratamiento de la seguridad social al trabajo de la mujer en el propio hogar y facilitar al máximo el trabajo a domicilio.

- Ayudas fiscales y asistenciales a las familias que tienen a su cargo personas impedidas o necesitadas de cuidado continuo.

- Una adecuada política de orientación familiar. El CDS considera prioritaria la erradicación de las causas sociales e individuales de todo tipo que inducen a la existencia del aborto, para lo cual propone la inmediata creación de un programa de educación sexual y de información de los métodos anticonceptivos.

- Creación de centros públicos de orientación familiar.

- Si bien se declara contrario al aborto, el CDS considera necesaria y urgente una reforma de la legislación penal en esta materia, con la fijación de una serie progresiva de atenuantes e incluso de eximentes basadas fundamentalmente en circunstancias subjetivas y objetivas relacionadas con la mujer que aborta, haciendo más humana dicha legislación.

\section{RELACIONES LABORALES}

El CDS considera las relaciones laborales en una democracia industrial como instrumento básico de dignificación del trabajador y de garantía de sus derechos; este objetivo básico debe conciliarse con la estabilidad de la empresa y con una defensa de la productividad en razón de la competitivad propia de la economía de mercado y consecuencia también de la internacionalización de la economía.

En base a estos planteamientos, el CDS propugna las siguientes medidas:

- Reducción de la jornada de trabajo y ampliación de las vacaciones con carácter general y mínimo, sin perjuicio de lo que determinen los convenios colectivos correspondientes.

- Reducción general y gradual de la edad de jubilación de acuerdo con las posibilidades del sistema.

- Máxima atención a la política de prevención de accidentes de trabajo y mayor rigor en la inspección en esta materia.

- Mantenimiento, como regla general, del contrato indefinido y ampliación de la contratación temporal como instrumento de adecuación a las necesidades específicas de la empresa y de creación de empleo. 
- Potenciación del Instituto de Mediación, Arbitraje y Conciliación para la más rápida solución de los conflictos laborales y puesta en marcha de los Tribunales Arbitrales.

- Mayor flexibilidad en la contratación para las empresas con menos de veinticinco trabajadores y aportación para ellas del Fondo de Garantía Salarial en las indemnizaciones por rescisión del contrato.

\section{SANIDAD}

El CDS propone una política sanitaria efectiva y realista sin dogmatismos y sin el exclusivo objeto de defender intereses particulares o de grupo. En este sentido se declara partidario de la humanización de las relaciones sanitarias, de una atención integral de la salud, de la medicina preventiva, de la medicina comunitaria y de una medicina asistencial y reparadora.

Respecto a la Administración sanitaria, el CDS la concibe como un servicio público gestionado por un ente de administración institucional (INSALUD), en el que deben unificarse todas las competencias sanitarias a fin de evitar la actual dispersión administrativa y lograr la mayor eficacia sanitaria, respetando el patrimonio intelectual e individual del profesional.

\section{POLITICA ECONOMICA}

El CDS estima que, junto a la política económica orientada a conseguir una nueva industrialización, la gestión económica del Gobierno a corto plazo ha de responder a los problemas que en el ámbito económico está generando la crisis. Contener la inflación, frenar el aumento del paro, atender a los parados, conseguir la mejor administración de los recursos públicos y alcanzar el crecimiento máximo de la producción posible en cada momento constituyen objetivos de esa gestión económica a corto plazo.

Para contener la inflación se procurará que, mediante una negociación responsable entre los sindicatos y empresarios, se logren tasas de crecimiento salarial que no supongan pérdida del poder adquisitivo de los trabajadores y no agoten el necesario crecimiento de la autofinanciación empresarial, permitiendo la participación de los asalariados en las ganancias derivadas de los aumentos de la productividad.

El aumento de paro habrá de frenarse mediante una política fiscal que partiría del necesario saneamiento del sector público y de una mayor racionalidad y eficacia en los distintos programas de gasto.

Por último, la política monetaria se deberá articular de modo que no haga énfasis exclusivo en el control de las tensiones inflacionistas.

Pilar Mellado Prado 